\title{
EPR study of effect of ascorbic acid on hair and feather samples in relation to eumelanins and pheomelanins
}

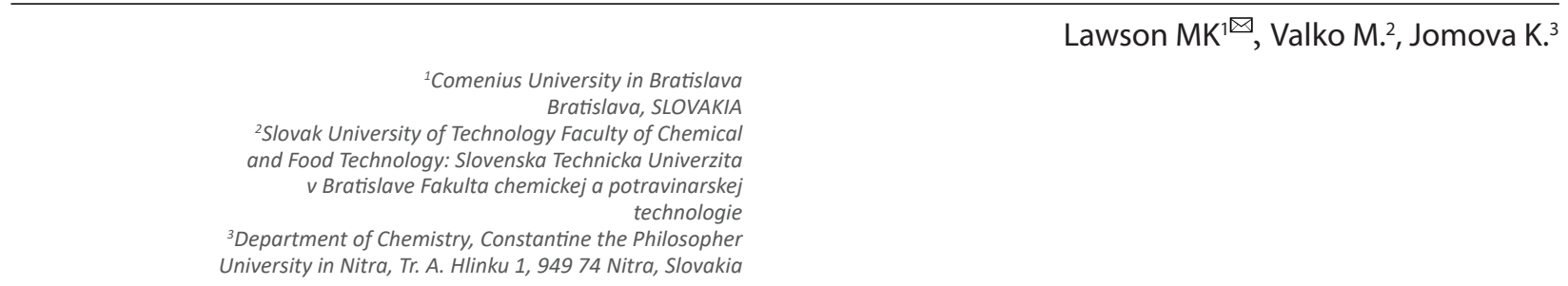

Received 11 June, 2021, accepted 17 June, 2021

Keywords hair melanin-feather melanin-eumelanin-pheomelanin-ascorbic acid-EPR (electron paramagnetic resonance spectroscopy)

\section{INTRODUCTION}

L-ascorbic acid is an antioxidant and an essential vitamin for the synthesis of collagen that is considered important for the youthful appearance of skin. It is a common ingredient of skin creams, but this may be unnecessary and even undesirable as I-ascorbic acid may also act as a pro-oxidant (Halliway \& Gutteridge, 2007).

In human hair and skin, there are two types of melanin: eumelanin and pheomelanin. Eumelanin gives hair and skin a dark colour and is usually considered beneficial as an antioxidant and a metal chelator (Felix et al., 1978). Pheomelanin gives brown and red hair its yellow-like colour. It is also likely to be present in the skin of red-haired individuals (Thody et al., 1991). Pheomelanin might have some prooxidant effects both in the presence and absence of UV light (Mitra et al., 2012).

Electron paramagnetic resonance (EPR) is a tool which investigates molecular species with unpaired electrons. Free radicals such as hydroxyl radicals, believed to cause cumulative cell damage, are EPR-silent because they are short-lived, but can be detected indirectly using the so-called spin traps. Antioxidants like ascorbic acid are believed to neutralise hydroxyl radicals by transferring unpaired electron onto themselves and then forming non-radical species. Ascorbic acid in aqueous solution is also EPR-silent as its free radical form is also short-lived. Melanins are stable free radicals which give a clear EPR signal. The stability of the free radical means that the free radical is not normally transferred to a water molecule to form a harmful hydroxyl radical.

\section{MATERIALS AND METHODS}

Ten samples of various browns from honey blonde to dark brown, four samples of red hair and four samples of black hair were taken from human volunteers. Red hen feathers as were also obtained well as black crow feathers.

Locks of hair, of about $3 \mathrm{~cm}$ length and $0.7 \mathrm{~cm}$ thickness, were tied with white cotton thread and suspended in ascorbic acid solutions of $0.0,0.1,1,10$ and $100 \mathrm{mM}$ for 24 hours and then dried. The samples were cut into small pieces, put into an EPR measuring tube and the EPR signal was measured. The same procedure was done for control (untreated hair), except that the samples were left in deionised water for 24 hours.

To obtain the accurate $g$ values, a manganese ion standard, enclosed in a sealed thin glass tube, was inserted into the EPR tube with the hair/feather sample and the $g$ value of the sample was calculated using the formula [1]:

$g_{\text {corr }}=\frac{g_{L} \times g_{R}}{g_{R}+\left|g_{L}-g_{R}\right| \times \frac{r}{d}}$

where $d$ is the difference in measured $g$ values between the third and fourth hyperfine lines of the manganese ion standard, $r$ is the difference in measured $g$ values between the 
Table 1. $g$ Values for different hair colour types and their comparison on treatment with ascorbic acid.

\begin{tabular}{|c|c|c|}
\hline Hair type & $\begin{array}{c}\text { Soaked in water } \\
\text { for } \mathbf{2 4} \text { hours }\end{array}$ & $\begin{array}{c}\text { Soaked in } \mathbf{1 0} \mathbf{~ m M} \\
\text { ascorbic acid for } \\
\mathbf{2 4} \text { hours }\end{array}$ \\
\hline Black & 2.0039 & 2.0039 \\
\hline Brown & 2.0044 & 2.0057 \\
\hline Red & 2.0051 & 2.0056 \\
\hline Red hen feather & 2.0054 & 2.0057 \\
\hline
\end{tabular}

EPR signal produced by the sample and the third hyperfine line of the manganese standard, $g_{L}$ is the standard value of the manganese third line taken to be 2.0330 and $g_{R}$ is the standard value of the fourth hyperfine line of manganese ion standard taken to be 1.9810 .

\section{RESULTS}

The EPR signal changed only slightly for black hair and black crow feather samples (Table 1). For brown, red hair and red hen samples, the changes were much more significant (Table 1 and Figure 1). Furthermore, for some of brown and red hair samples, there was a clear change in the amplitude of the EPR signal (Lawson et al., 2021).

\section{DISCUSSION}

The EPR signal of eumelanin-rich samples was not affected much; so, ascorbic acid probably caused little change. In contrast, pheomelanin seems to be strongly affected by ascorbic acid. The signal amplitude increase could be because pheomelanin, in the presence of ascorbic acid, induces the creation of free radicals which are then trapped by pheomelanin. These free radicals may not all be trapped and/or could do damage prior to being trapped (whether by pheomelanin, small portion of eumelanin or ascorbic acid). An alternative explanation is that the brown and red hair samples showed increased EPR signal due to the samples being hydrated. Ascorbic acid would then push the

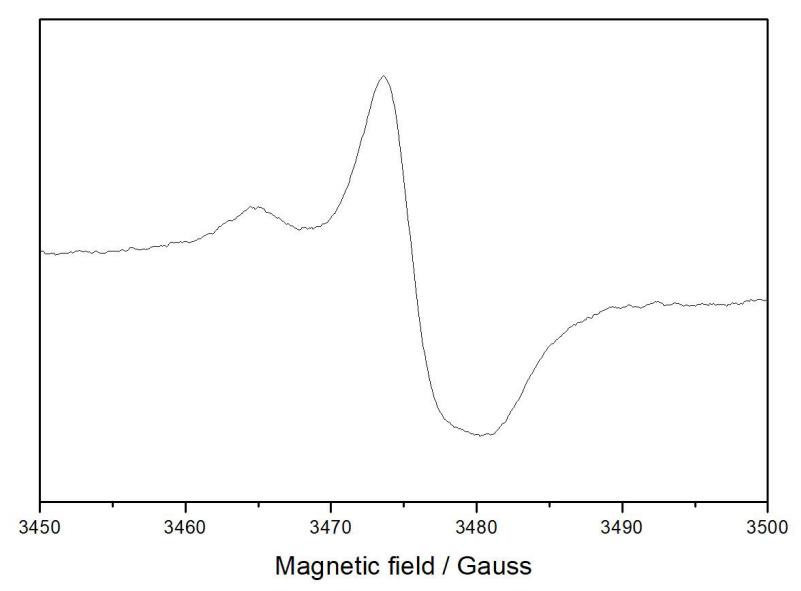

(a)

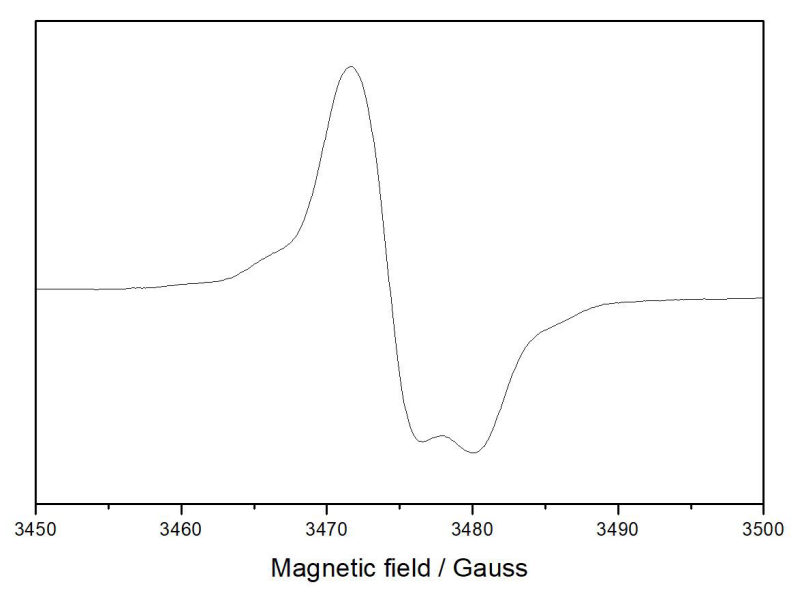

(b)

Figure 1. (a) EPR signal for red hair sample soaked in water for 24 hours and dried (left); (b) EPR signal for red hair sample soaked in $100 \mathrm{mM}$ ascorbic acid solution for 24 hours and dried (right).

equilibrium away from the fully oxidised and reduced forms to semi-oxidised (free radical) form (d'Ischia et al., 2013; Sealy et al., 1982). This presumably would not create other free radical species if the exchange of electrons is directly between the oxidised and reduced forms of pheomelanin. Clearly, further experiments using spin traps could clarify whether hydroxyl radicals are being generated.

\section{References}

[1] d'Ischia MD, Wakamatsu K, Napolitano A, Briganti S, Garcia-Borron J, Kovacs D, Meredith P, Pezzella A, Picardo M, Sarna T, Simon JD, Ito S. Melanins and melanogenesis: methods, standards, protocols. Pigment Cell Melanoma Res. 2013;26;616-633.

[2] Felix CC, Hyde JS, Sarna T, Sealy RC. Interactions of melanin with metal ions. Electron spin resonance evidence for chelate complexes of metal ions with free radicals. J Am Chem Soc. 1978;100; 3922-3926.
[3] Halliway B, Gutteridge JMC. Free Radicals in Biology and Medicine. 4th Edition; Oxford,UK: Oxford University Press; 2007. (pp. 42-43, pp. 160-166).

[4] Lawson MK, Valko M, Jomova K. EPR study of effect of ascorbic acid on hair and feather samples in relation to eumelanins and pheomelanins. Short talk presented at: 12th World Meeting on Pharmaceutics, Biopharmaceutics and Pharmaceutical Technology, May 13, 2021; Vienna (online). 
[5] Mitra D, Luo X, Morgan A, Wang J, Hoang MP, Lo J, Guerrero CR, Lennerz JK, Mihm MC, Wargo JA, Robinson KC, Devi SP, Vanover JC, D'Orazio DA, McMahon M, Bosenberg MW, Haigis KM, Haber DA, Wang $Y$, Fisher DE. An ultraviolet-radiation-independent pathway to melanoma carcinogenesis in the red hair/fair skin background. Nature. 2012;491;449-453.

[6] Thody AJ, Higgins EM, Wakamatsu K, Ito S, Burchill SA, Marks $J M$. Pheomelanin as well as eumelanin is present in human epidermis. J Invest Dermatol. 1991;97;340-44. 